\title{
Risk Factors Associated with Progression in Exfoliative Glaucoma Patients
}

\author{
Gábor Holló $^{a} \quad$ Luciano Quaranta $^{\mathrm{b}} \quad$ Barbara Cvenkel $^{\mathrm{d}}$ Yuri S. Astakhov \\ Miguel A. Teus ${ }^{f}$ Péter Kóthy ${ }^{a}$ Stefano Miglior ${ }^{c}$ Ivano Rivab \\ Evgeny L. Akopov ${ }^{\mathrm{e}}$ Juan Gros ${ }^{f} \quad$ Jeanette A. Stewart ${ }^{g} \quad$ Michael S. Kristoffersen $^{g}$ \\ Lindsay A. Nelson ${ }^{g}$ William C. Stewart ${ }^{9}$ \\ ${ }^{a}$ Semmelweis University, Budapest, Hungary; ${ }^{b}$ University of Brescia, Brescia, and ' University of Milan, Bicocca,

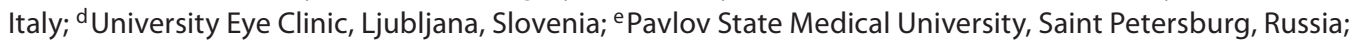 \\ f University of Alcalá, Madrid, Spain; ${ }^{9}$ PRN Pharmaceutical Research Network, LLC, Cheyenne, Wyo., USA
}

\section{Key Words}

Disc hemorrhage $\cdot$ Exfoliative glaucoma $\cdot$ Intraocular pressure $\cdot$ Progression $\cdot$ Risk factors

\begin{abstract}
Purpose: To evaluate exfoliative glaucoma (XFG) patients over 5 years, determining risk factors associated with progression or non-progression of glaucoma. Methods: A retrospective, observational study. Patients were chosen from consecutive charts and data collected from each available visit included in the follow-up period. Data were abstracted for non-progressed XFG patients for 5 years and for progressed patients until glaucoma worsened. Progression was determined from patient records and by disc photographs. Results: There were 71 (53\%) progressed and 63 (47\%) nonprogressed XFG patients. Baseline parameters demonstrated worse visual field damage $(p=0.014)$ and more prescribed medicines $(p=0.03)$ in progressed patients. The mean intraocular pressure (IOP) for progressed patients was $18.7 \pm 4.3$ and $17.3 \pm 3.4 \mathrm{~mm} \mathrm{Hg}$ for non-progressed patients $(p=$ 0.047). The mean IOP that best separated the groups was 17 $\mathrm{mm} \mathrm{Hg}$ with $60 \%$ staying non-progressed at or below this level and 30\% above this level. At the last visit, progressed patients had more medicines prescribed (1.7) than non-pro-
\end{abstract}

\section{KARGER}

Fax +4161306 1234 E-Mail karger@karger.ch www.karger.com
() 2011 S. Karger AG, Basel

0030-3747/12/0474-0208\$38.00/0

Accessible online at:

www.karger.com/ore gressed patients $(1.3, p=0.005)$. A multivariate regression analysis showed higher mean, peak and variance of IOP, number of glaucoma medications at the final visit and presence of a disc hemorrhage $(n=5)$ as independent risk factors for progression ( $p \leq 0.05$ ). Conclusion: IOP reduction in XFG may be essential in reducing disease progression. The presence of disc hemorrhage in XFG may suggest an increased probability of progression despite treatment to within the normal IOP range.

Copyright $\odot 2011$ S. Karger AG, Basel

\section{Introduction}

Exfoliative glaucoma is the most common type of secondary open-angle glaucoma [1]. Compared to primary open-angle glaucoma, it is frequently a more severe and more rapidly progressing disease [1-4]. Most authors have found that untreated intraocular pressure is higher in exfoliative glaucoma than in primary open-angle glaucoma [5-10]. Further, exfoliative glaucoma may be associated with greater visual field loss as well as more rapid progression of visual field and optic nerve damage than primary open-angle glaucoma $[1,2,11]$. Accordingly, treatment of exfoliative glaucoma may be more difficult 
with a higher incidence of therapeutic failure, requiring more aggressive therapy, than primary open-angle glaucoma $[4,12-14]$.

Unfortunately, data on exfoliative glaucoma patients' treatment endpoints that would help to prevent their glaucomatous progression are limited. In 2004, Konstas et al. [15] suggested that in exfoliative glaucoma patients the long-term mean intraocular pressure which best prevented progression was $\leq 17 \mathrm{~mm} \mathrm{Hg}$. However, some patients progressed despite lowering the pressure to $\leq 17$ $\mathrm{mm} \mathrm{Hg}$. Consequently, other risk factors for progression may exist in certain exfoliative glaucoma patients who, to date, have not been identified.

Recently, Holló et al. [16] evaluated the presence of cardiovascular disease as a potential risk factor for progression of exfoliative glaucoma. Although the results were not conclusive, the study suggested that patients with a history of cardiovascular disease might require a slightly lower target intraocular pressure to prevent progression $(18 \mathrm{~mm} \mathrm{Hg})$ than those without $(20 \mathrm{~mm} \mathrm{Hg})$. This finding also suggests that additional, probably vascular risk factors of progression in exfoliative glaucoma need to be identified.

The purpose of the current study was to determine risk factors associated with progression or non-progression of exfoliative glaucoma using clinical data registered during a 5-year follow-up period.

\section{Patients and Methods}

\section{Patients}

The trial was performed in five centers across Europe in Hungary, Italy, Slovenia, Russia and Spain. The study design was a retrospective, observational study of a single cohort. Since this was a retrospective analysis requiring no patient identifiers, an ethics committee approval was not required at any of the participating research centers.

We included in this study patients with: a minimum of 5 years of records with a diagnosis of non-progressed or progressed exfoliative glaucoma (based on typical anterior segment findings of exfoliation syndrome, glaucomatous optic disc and/ or nerve fiber layer changes, and/or glaucomatous visual field defect). Glaucomatous optic nerve head changes were characterized with neuroretinal rim thinning or notching, saucerization, thin nasal rim or total cupping. Visual field changes typical for glaucoma comprised nasal step or paracentral, Seidel's or arcuate scotoma. Included patients had to have at least seven visits with a documented intraocular pressure value and at least three sets of documented disc examinations (photographs, detailed disc drawings or HRT analyses) recorded during the 5-year follow-up period within \pm 12 months of the first and final visits, respectively. Patients must have demonstrated typical anterior chamber findings of exfoliation syndrome including: exfolia- tion material deposits on the lens surface, Sampaolesi's line with irregular trabecular meshwork pigmentation by gonioscopy, moth-eaten pupillary margin and iris transillumination defects at the sphincter area [15].

We excluded patients from this study who had progressive non-glaucomatous visual loss; refractive surgery in the study eye before or during the study period; any abnormality that prevented reliable applanation tonometry; intraocular conventional or laser surgery less than 3 months prior to the first abstracted visit; media opacity preventing reliable optic nerve head or visual field evaluation at the first and last abstracted visit; primary, acute or chronic angle closure; secondary as well as congenital glaucoma; known occludable angles by gonioscopy or presence of any other clinically significant angle abnormalities, or who had been enrolled in a prospective clinical trial during the follow-up period.

\section{Procedures}

Patients were chosen from consecutive charts from the practices of the study investigators and reviewed alphabetically. Data collections began from the patient's initial examination by the investigator and were recorded from each available visit included in the follow-up period. Data were abstracted for non-progressed exfoliative glaucoma patients for 5 years. In contrast, data were abstracted for progressed exfoliative glaucoma patients until the time the glaucoma worsened. Data were not abstracted after the time of progression so the information included in this study would reflect the ocular condition that worsened the glaucoma.

Data recorded from each visit included: intraocular pressure determined using Goldmann applanation tonometry, glaucoma therapeutic procedures, date of visits, dilated optic disc and visual field examinations. The same investigator supervised each patient during the follow-up period. The patient's ophthalmic and limited systemic medical history (cardiovascular, systemic hypertension, diabetes, and dyslipidemia), pachymetry and demographics were collected at the first visit. Data on ophthalmic medication, cup/disc ratio, best corrected visual acuity and the visual field results were collected both at the first and last visits.

Progression was determined from the investigator's clinical notations in the patients' records. In each case progression was noted in the chart with the associated reason. Generally, criteria for progression were an increase in thinning of the neuroretinal rim or a reproducible worsening of glaucomatous visual field loss. In patients with total glaucomatous cupping and diffusely depressed visual fields, worsening of the best corrected visual acuity could also be used as the last any only measurable sign of progression. Patients without 'progression' noted were assumed non-progressed.

\section{Statistics}

PRN Pharmaceutical Research Network, LLC, analyzed the data. If both eyes of a patient met the criteria for entrance into the study, one eye was randomly chosen to be analyzed. All analyses were two sided and unpaired. A value of 0.05 was selected to determinate statistical significance.

An ANOVA test was used to analyze data for: age, mean and peak intraocular pressures, number of office visits, the number of medicines prescribed at baseline and at the end of the study follow-up period, the study term in years, baseline pachymetry, cup/ disc ratio, visual acuity, the number of laser trabeculoplasties and trabeculectomies, and systemic history $[17,18]$. The F test was 
Table 1. Baseline patient characteristics (mean \pm SD value or number of patients)

\begin{tabular}{llccc}
\hline Characteristics & Detail & Progressed & Non-progressed & p value \\
\hline Patients & & 71 & 63 & 0.17 \\
\hline Age, years & & $69.9 \pm 8.2$ & $68.0 \pm 8.1$ & 0.03 \\
\hline Glaucoma medicines, $\mathrm{n}$ & & $1.3 \pm 0.9$ & $1.0 \pm 0.7$ & 0.24 \\
\hline Visual acuity & & $0.8 \pm 0.3$ & $0.9 \pm 0.3$ & 0.10 \\
\hline Pachymetry, $\mu \mathrm{m}$ & & $535.2 \pm 30.9$ & $544.8 \pm 31.0$ & 0.33 \\
\hline Cup/disc ratio & Vertical & $0.6 \pm 0.3$ & $0.6 \pm 0.2$ & 0.09 \\
\hline Systemic history & Horizontal & $0.6 \pm 0.3$ & $0.5 \pm 0.3$ & 0.44 \\
& Cardiovascular history & 9 & 11 & 0.69 \\
& Systemic hypertension & 28 & 27 & 0.64 \\
\hline Study eye & Diabetes & 6 & 4 & 0.55 \\
\hline Gender & Dyslipidemia & 2 & 3 & 0.12 \\
\hline Visual field diagnoses & Right & 40 & 27 & 0.23 \\
& Left & 31 & 36 & 0.014 \\
\hline & Male & 31 & 29 & \\
\hline
\end{tabular}

The bold line divides the characteristics of the statistical test used: above the bold line a one-way ANOVA test and below a $\chi^{2}$ or Fisher's exact test.

used to analyze the difference in the variance (the square of the standard deviation) of the individual patient's intraocular pressures measured during the follow-up period, between progressed and non-progressed patients [17].

A $\chi^{2}$ or Fisher's exact test was used to analyze differences in non-ordered scores such as: visual field diagnoses, left or right eye, gender, and the incidence of disc hemorrhage [17, 19]. The target for the intraocular pressure which best prevented glaucomatous progression was determined and described, but was not analyzed statistically. Risk factors for glaucomatous progression were also analyzed by a multivariate regression analysis.

\section{Results}

\section{Baseline Measures}

We included 134 exfoliative glaucoma patients in this study of whom 71 (53\%) were progressed and 63 (47\%) non-progressed. Table 1 shows the baseline characteristics of patients who were progressed and non-progressed over the 5-year follow-up period. At baseline, there was no statistical difference between groups for any clinical or historical parameter except for a greater number of glaucoma medicines $(p=0.03)$ and more visual field damage $(\mathrm{p}=0.014)$ in patients who later progressed.
Table 2. Follow-up measures (mean \pm SD value or number of patients)

\begin{tabular}{lccc}
\hline Follow-up measures & $\begin{array}{l}\text { Pro- } \\
\text { gressed }\end{array}$ & $\begin{array}{l}\text { Non- } \\
\text { progressed }\end{array}$ & $\begin{array}{l}\mathrm{p} \\
\text { value }\end{array}$ \\
\hline Patients & 71 & 63 & \\
Office visits, n & $7.5 \pm 4.7$ & $9.0 \pm 5.3$ & 0.07 \\
Glaucoma medicines, n & $1.7 \pm 0.9$ & $1.3 \pm 0.8$ & 0.005 \\
Study term, years & $3.4 \pm 2.1$ & $5.3 \pm 0.5$ & $<0.001$ \\
Laser trabeculoplasty & $0.1 \pm 0.3$ & $0.0 \pm 0.2$ & 0.24 \\
Trabeculectomy & $0.1 \pm 0.4$ & $0.2 \pm 0.4$ & 0.47 \\
Mean intraocular pressure & $18.7 \pm 4.3$ & $17.3 \pm 3.4$ & 0.047 \\
Peak intraocular pressure & $25.0 \pm 7.1$ & $25.1 \pm 6.9$ & 0.96 \\
\hline Presence of disc hemorrhage & & & \\
$\quad$ Yes & 5 & 0 & 0.06 \\
$\quad$ No & 66 & 63 & \\
\hline Variance of intraocular pressure & 24.5 & 19.7 & $<0.001$ \\
\hline
\end{tabular}

The bold lines divide the characteristics by the statistical test used: the top group using one-way ANOVA test, the middle $\chi^{2}$ or Fisher's exact test, and the bottom F-test. 


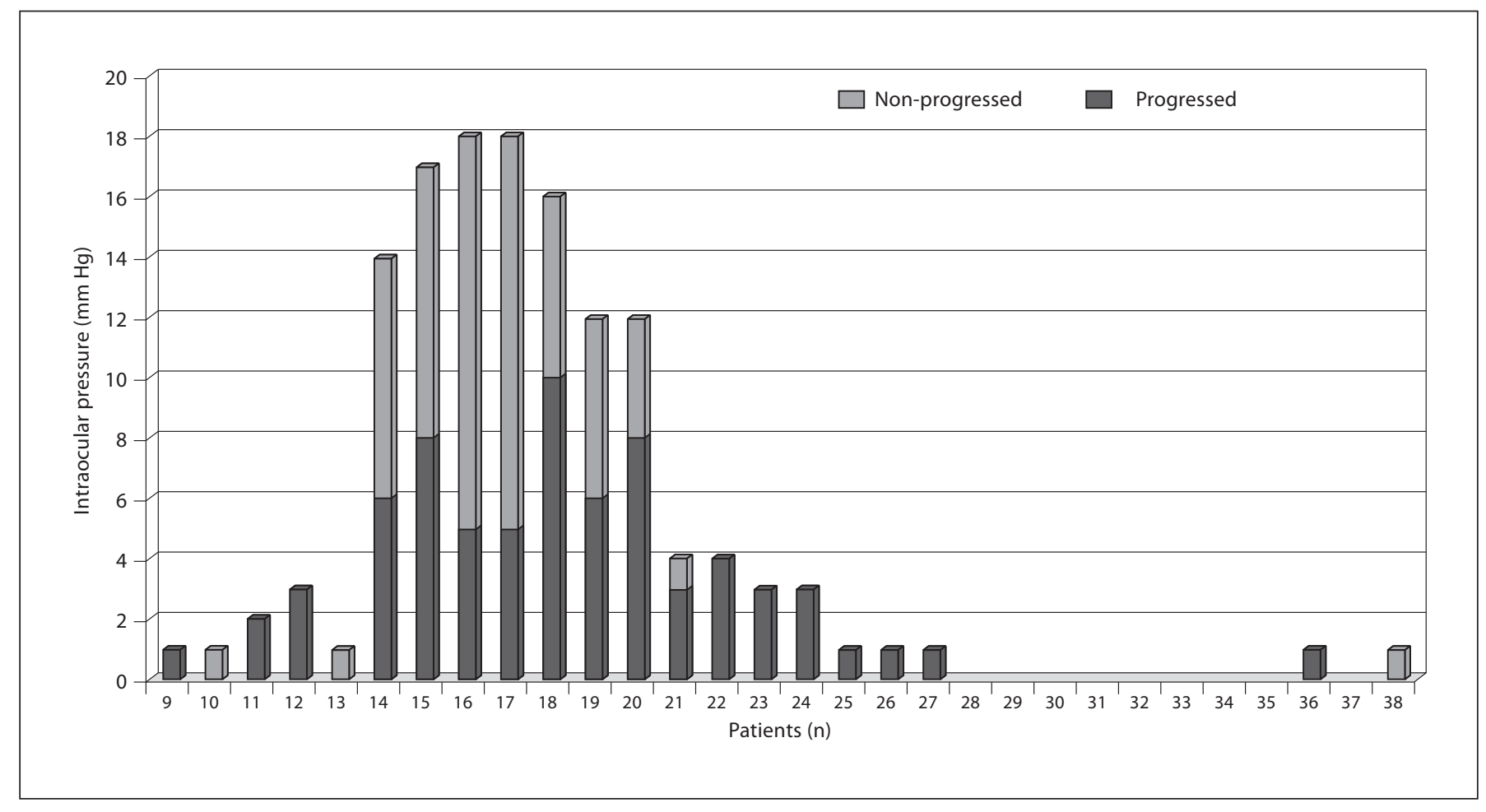

Fig. 1. The number of patients who progressed or were non-progressed at each mean intraocular pressure.

Table 3. Risk factors for progression by multivariate regression analysis

\begin{tabular}{ll}
\hline Risk factors & p value \\
\hline Disc hemorrhage & 0.05 \\
Age & 0.94 \\
Systemic history & 0.59 \\
Gender & 0.14 \\
Mean intraocular pressure & 0.003 \\
Peak intraocular pressure & 0.002 \\
Variance of intraocular pressure & 0.01 \\
Glaucoma medications at baseline & 0.35 \\
Glaucoma medications at final visit & 0.02 \\
\hline
\end{tabular}

\section{Follow-Up Parameters}

The clinical follow-up parameters are presented in table 2. Progressed patients, as expected by the trial design of the study, had a shorter follow-up time $(\mathrm{p}<0.001)$. At the last visit, progressed patients also had more medicines prescribed $(p=0.005)$ as well as over the follow-up period a higher mean intraocular pressure $(\mathrm{p}=0.047)$ and mean variance of the pressure $(\mathrm{p}<0.001)$.

Risk Factors Associated with Progression in Exfoliative Glaucoma Patients
Figure 1 shows the number of patients who progressed or were non-progressed at each mean pressure. The mean pressure which best separated non-progressed from progressed patients was $17 \mathrm{~mm} \mathrm{Hg}$ with 60\% (45/75) staying non-progressed below this level and 40\% (30/75) progressed. Above this level, 30\% (18/59) remained non-progressed and 70\% (41/59) progressed.

\section{Regression Analysis}

The results of the multivariate regression analysis are shown in table 3 . The mean, peak and variance of intraocular pressure, the number of glaucoma medications at the final visit and the presence of a disc hemorrhage were the only independent risk factors for progression ( $\mathrm{p} \leq$ 0.05).

\section{Discussion}

The purpose of the current study was to determine risk factors associated with progression or non-progression of exfoliative glaucoma using clinical data registered during a 5-year follow-up period.

Ophthalmic Res 2012;47:208-213 
In the current study we found that $53 \%$ of our exfoliative glaucoma patients under treatment progressed based on structural and/or functional findings over a 5-year follow-up period. The mean variance of the pressure was statistically higher in progressed $(24.5 \mathrm{~mm} \mathrm{Hg})$ than in non-progressed patients $(19.7 \mathrm{~mm} \mathrm{Hg})$. A higher variance was also previously found as a risk factor for progression in exfoliative patients by Konstas et al. [15].

This study also found that the mean pressure was statistically higher in progressed $(18.7 \mathrm{~mm} \mathrm{Hg})$ than in nonprogressed patients $(17.3 \mathrm{~mm} \mathrm{Hg}$ ). The mean pressure which best separated non-progressed from progressed patients was approximately $\leq 17 \mathrm{~mm} \mathrm{Hg}$. At or below this cut-off value, $60 \%$ of the exfoliative glaucoma eyes did not show progression, while at higher mean intraocular pressure values only $30 \%$ of the eyes remained non-progressed. This finding is consistent with the results of earlier studies by Konstas et al. [15] as well as Holló et al. [16] that in exfoliative glaucoma patients the pressure level that best separated progression and nonprogression over 5 years was approximately $17 \mathrm{~mm} \mathrm{Hg}$. In addition, this pressure level is similar to that found for primary open-angle glaucoma in a number, but not all studies [20-24].

Further, in several previous investigations it has been shown that the mean intraocular pressure is an independent risk factor for progression both in exfoliative glaucoma and primary open-angle glaucoma by multivariate regression analysis [15, 23, 25-29]. In the current study, again the mean pressure, as well as the peak and variance of the pressure, were identified statistically as risk factors for progression. Nonetheless, despite the intraocular pressure control achieved in our current study to $\leq 17$ $\mathrm{mm} \mathrm{Hg}$, similarly to previously published results, $40 \%$ of the exfoliative glaucoma eyes still progressed [15]. This number is generally higher than the number reported for primary open-angle glaucoma at similar intraocular pressure levels [20-25].

The reason that some patients progressed even with a reduced intraocular pressure has not been clarified. Since in exfoliative glaucoma cardiovascular regulation has been shown to be altered and damaged, it has been proposed that patients progressing despite well-controlled pressure may have resulted from a compromised cardiovascular system [30-35]. Nonetheless, although many of our patients had a history of cardiovascular disease, the incidence was similar between progressed and non-progressed patients.

However, all disc hemorrhages in our study were found in the group of progressed patients. A multivariate regression analysis demonstrated that disc hemorrhage was a risk factor for progression of exfoliative glaucoma in our study. Bengtsson et al. [25] recently noted in a mixed primary open-angle/exfoliative glaucoma population from data obtained in the Early Manifest Glaucoma Trial, that the occurrence of a disc hemorrhage was independent of intraocular pressure achieved with treatment. In exfoliative glaucoma, as in primary open-angle glaucoma, a disc hemorrhage is considered to portend glaucomatous progression [34-37]. Although the number of patients with disc hemorrhage in our study was small $(n=5)$, our results may indicate an increased risk for progressive glaucomatous damage in the presence of this finding $[26,36]$.

In addition, at baseline, our progressed patients demonstrated more advanced glaucomatous damage and an increased need for medication at baseline, as compared to the non-progressed patients. Thus, their more advanced disease may have predisposed the progressed group towards further damage during follow-up, despite effective intraocular pressure reduction.

Our results suggest that intraocular pressure reduction in exfoliative glaucoma both with and without disc hemorrhage is essential to reduce disease progression. However, the presence of a disc hemorrhage in exfoliative glaucoma may indicate an increased probability of progression despite treatment to within the normal intraocular pressure range.

The clinical importance of our data may be that exfoliative glaucoma patients should be followed carefully because of the high likelihood of progression despite an intraocular pressure level within the normal pressure range, under treatment. Further, the presence of a disc hemorrhage may suggest an increased risk for progression in exfoliative glaucoma, and may indicate a need for more intensive patient control and more aggressive intraocular pressure reduction. Nonetheless, prospective investigations are necessary to clarify the exact role of optic nerve head hemorrhages in the progression of exfoliative glaucoma under effective intraocular pressure-lowering treatment to long-term mean intraocular pressure $<17$ $\mathrm{mm} \mathrm{Hg}$.

\section{Disclosure Statement}

The authors have no conflicts of interest to disclose. 


\section{References}

$\checkmark 1$ Hejl A, Bengtsson B, Hyman L, Leske MC: Natural history of open-angle glaucoma. Ophthalmology 2009;116:2271-2276.

-2 Ritch R, Schlötzer-Schrehardt U: Exfoliation syndrome. Surv Ophthalmol 2001;45:265315.

-3 Ritch R, Schlötzer-Schrehardt U, Konstas AG: Why is exfoliation syndrome associated with glaucoma? Prog Retinal Eye Res 2003; 22:253-275

$\checkmark 4$ Vesti E, Kivela T: Exfoliation syndrome and exfoliation glaucoma. Prog Retinal Eye Res 2001;19:345-368

5 Konstas AG, Mantziris DA, Stewart WC: Diurnal intraocular pressure in untreated exfoliation and primary open-angle glaucoma. Arch Ophthalmol 1997;115:182-185.

-6 Konstas AG, Stewart WC, Stroman GA, Sine CS: Clinical presentation and initial treatment patterns in patients with exfoliation glaucoma versus primary open-angle glaucoma. Ophthalmic Surg Lasers 1997;28:111117.

7 Tezel G, Tezel TH: The comparative analysis of optic disc damage in exfoliative glaucoma. Acta Ophthalmol 1993;71:744-750.

$\checkmark 8$ Lindblom B, Thorburn W: Functional damage at diagnosis of primary open angle glaucoma. Acta Ophthalmol 1984;62:223-229.

-9 Futa R, Shimizu T, Furuyoski N, Nishiyama M, Hagihara O: Clinical features of capsular glaucoma in comparison with primary open-angle glaucoma in Japan. Acta Ophthalmol (Copenh) 1992;70:214-219.

-10 Linnér E, Schwartz B, Araujo D: Optic disc pallor and visual field defect in exfoliative and non-exfoliative, untreated ocular hypertension. Int Ophthalmol 1989;13:21-24.

- 11 Teus MA, Castejon MA, Calvo MA, PérezSalaíces P, Marcos A: Intraocular pressure as a risk factor for visual field loss in pseudoexfoliative and in primary open-angle glaucoma. Ophthalmology 1998;105:2225-2230.

$\checkmark 12$ Brooks AMV, Gillies WE: The presentation and prognosis of glaucoma in pseudoexfoliation of the lens capsule. Ophthalmology 1988;95:271-276.

$\checkmark 13$ Blika S, Saunte E: Timolol maleate in the treatment of glaucoma simplex and glaucoma capsulare. Acta Ophthalmol (Copenh) 1982;60:967-976
14 Pohjanpelto P: Influence of exfoliation syndrome on prognosis in ocular hypertension. Acta Ophthalmol 1986;64:39-44.

15 Konstas AG, Hollo G, Astakhov YS, Teus MA, Akopov EL, Jenkins JN, Stewart WC: Factors associated with long-term progression or stability in exfoliation glaucoma. Arch Ophthalmol 2004;122:29-33.

16 Holló G, Cvenkel B, Teus MA, Irkec MT, Astakhov YS, Chiselita D, Petkova N, Liehneová I, Kaluzny BJ, Kóthy P, Bozkurt B, Akopov EL, Stewart JA, Kristoffersen MS, Kristoffersen CJ, Stewart WC: Is there any difference in target intraocular pressure for exfoliative glaucoma patients with cardiovascular disease history? Eur J Ophthalmol 2010;20:1000-1006.

17 Book SA: Essentials of Statistics. New York, McGraw-Hill, 1978, vol 122, p 205.

18 Swinscow TD: Statistics at Square One. London, British Medical Association, 1976, pp 54-57.

19 Moses LE, Emerson JD, Hosseini H: Statistics in practice. Analyzing data from ordered categories. N Engl J Med 1984;311:442.

20 Mao LK, Stewart WC, Shields MB: Correlation between intraocular pressure control and progressive glaucomatous damage in primary open-angle glaucoma. Am J Ophthalmol 1991;111:51-55.

21 Stewart WC, Chorak RP, Hunt HH, Sethuraman G: Factors associated with visual loss in patients with advanced glaucomatous changes in the optic nerve head. Am J Ophthalmol 1993;116:176-181.

22 Stewart WC, Kolker AE, Sharpe ED, Day DG, Holmes KT, Leech JN, Johnson M, Cantrell JB: Factors associated with longterm progression or stability in primary open-angle glaucoma. Am J Ophthalmol 2000;130:274-279.

23 Stewart WC, Kolker AE, Sharpe ED, Day DG, Konstas AG, Hollo G, Astakhov YS Teus MA, Stewart JA: Long-term progression at individual mean intraocular pressure levels in primary open-angle and exfoliative glaucoma. Eur J Ophthalmol 2008;18:765770.

24 The AGIS Investigators: The Advanced Glaucoma Intervention Study (AGIS). 7. The relationship between control of intraocular pressure and visual field deterioration. Am J Ophthalmol 2000;130:429-440.

-25 Bengtsson B, Leske MC, Yang Z, Heijl A Disc hemorrhages and treatment in the early manifest glaucoma trial. Ophthalmology 2008;115:2044-2048.
26 Ritch R: The Glaucomas. St Louis, MosbyYearbook, 1996, pp 1426-1430.

-27 Seong GJ, Rho SH, Kim CS, Moon JI, Kook MS, Kim YY, Ma KT, Hong YJ, Nelson LA, Kruft B, Stewart JA, Stewart WC: Potential benefits of intraocular pressure reduction in normal-tension glaucoma in South Korea. J Ocul Pharmacol Ther 2009;25:91-96.

28 Nouri-Mahdavi K, Hoffman D, Coleman AL, Liu G, Li G, Gaasterland D, Caprioli J: Predictive factors for glaucomatous visual field progression in the Advanced Glaucoma Intervention Study. Ophthalmology 2004; 111:1627-1635.

29 Caprioli J, Coleman AL: Intraocular pressure fluctuation a risk factor for visual field progression at low intraocular pressures in the advanced glaucoma intervention study. Ophthalmology 2008;115:1123-1129.

30 Holló G, Lakatos P, Farkas K: Cold pressor test and plasma endothelin-1 concentration in primary open-angle and capsular glaucoma. J Glaucoma 1998;7:105-110.

31 Visontai Zs, Merisch B, Kollai M, Hollo G: Increase of carotid artery stiffness and decrease of baroreflex sensitivity in exfoliation syndrome and glaucoma. Br J Ophthalmol 2006;90:563-567.

>32 Visontai Zs, Horváth T, Kollai M, Hollo G: Decreased cardiovagal regulation in exfoliation syndrome. J Glaucoma 2008;17:133138.

33 Bojic L, Ermacora R, Polic S, Ivanisević M, Mandić Z, Rogosić V, Lesin M: Pseudoexfoliation syndrome and asymptomatic myocardial dysfunction. Graefes Arch Clin Exp Ohthalmol 2005;243:446-449.

34 Prata TS, De Moraes CG, Teng CC, Tello C, Ritch R, Liebmann JM: Factors affecting rates of visual field progression in glaucoma patients with optic disc hemorrhage. Ophthalmology 2010;117:24-29.

35 Leske MC, Heijl A, Hyman L, Bengtsson B, Dong L, Yang Z: Predictors of long-term progression in the early manifest glaucoma trial. Ophthalmology 2007;114:1965-1972.

36 Stewart WC: Clinical Practice of Glaucoma. Thorofare, SLACK Inc, 1990, pp 1-40, 149196.

37 Sonnsjö B, Dokmo Y, Krakau T: Disc haemorrhages, precursors of open angle glaucoma. Prog Retin Eye Res 2002;21:35-56. 